\title{
Age-related differences in enhancement and suppression of neural activity underlying selective attention in matched young and old adults
}

\section{Citation}

Haring, A.E., T.Y. Zhuravleva, B.R. Alperin, D.M. Rentz, P.J. Holcomb, and K.R. Daffner. 2013. "Age-Related Differences in Enhancement and Suppression of Neural Activity Underlying Selective Attention in Matched Young and Old Adults." Brain Research 1499: 69-79.

\section{Published Version}

10.1016/j.brainres.2013.01.003

\section{Permanent link}

http://nrs.harvard.edu/urn-3:HUL.InstRepos:32521793

\section{Terms of Use}

This article was downloaded from Harvard University's DASH repository, and is made available under the terms and conditions applicable to Other Posted Material, as set forth at http:// nrs.harvard.edu/urn-3:HUL.InstRepos:dash.current.terms-of-use\#LAA

\section{Share Your Story}

The Harvard community has made this article openly available.

Please share how this access benefits you. Submit a story.

\section{Accessibility}




\title{
Age-related differences in enhancement and suppression of neural activity underlying selective attention in matched young and old adults
}

\author{
A. E. Haring ${ }^{a}$, T. Y. Zhuravleva ${ }^{a}$, B. R. Alperin ${ }^{a}$, D. M. Rentz ${ }^{a}$, P. J. Holcomb ${ }^{b}$, and K. R. \\ Daffnera \\ ${ }^{a}$ Center for Brain/Mind Medicine, Division of Cognitive and Behavioral Neurology, Department of \\ Neurology, Brigham and Women's Hospital, Harvard Medical School, 221 Longwood Avenue, \\ Boston, MA 02115, USA \\ ${ }^{b}$ Department of Psychology, Tufts University, 490 Boston Avenue, Medford, MA 02155, USA
}

\section{Abstract}

Selective attention reflects the top-down control of sensory processing that is mediated by enhancement or inhibition of neural activity. ERPs were used to investigate age-related differences in neural activity in an experiment examining selective attention to color under Attend and Ignore conditions, as well as under a Neutral condition in which color was task-irrelevant. We sought to determine whether differences in neural activity between old and young adult subjects were due to differences in age rather than executive capacity. Old subjects were matched to two groups of young subjects on the basis of neuropsychological test performance: one using age-appropriate norms and the other using test scores not adjusted for age. We found that old and young subject groups did not differ in the overall modulation of selective attention between Attend and Ignore conditions, as indexed by the size of the anterior Selection Positivity. However, in contrast to either young adult group, old subjects did not exhibit reduced neural activity under the Ignore relative to Neutral condition, but showed enhanced activity under the Attend condition. The onset and peak of the Selection Positivity occurred later for old than young subjects. In summary, older adults execute selective attention less efficiently than matched younger subjects, with slowed processing and failed suppression under Ignore. Increased enhancement under Attend may serve as a compensatory mechanism.

\section{Keywords}

Visual Selective Attention; Aging; ERPs; Executive capacity; Top-Down Processing; Inhibition; Well-matched Subjects

\footnotetext{
(C) 2013 Elsevier B.V. All rights reserved.
}

Corresponding author: Kirk R. Daffner, M.D., Center for Brain/Mind Medicine, Division of Cognitive and Behavioral Neurology, Brigham and Women's Hospital, Harvard Medical School, 221 Longwood Avenue, Boston, MA 02115, USA (617) 732-8060 (phone); (617) 738-9122 (fax); kdaffner@ partners.org.

Publisher's Disclaimer: This is a PDF file of an unedited manuscript that has been accepted for publication. As a service to our customers we are providing this early version of the manuscript. The manuscript will undergo copyediting, typesetting, and review of the resulting proof before it is published in its final citable form. Please note that during the production process errors may be discovered which could affect the content, and all legal disclaimers that apply to the journal pertain. 


\section{Introduction}

Visual selective attention reflects top-down control of information processing based on task demands and is hypothesized to be primarily mediated by the executive control component of working memory (Desimone and Duncan, 1995; Lavie et al., 2004; Rutman et al., 2010). Although many studies suggest an age-related reduction in selective attention, especially the capacity to ignore task-irrelevant distracters (de Fockert et al., 2009; Gazzaley et al., 2008; Lustig et al., 2007; West, 1999), there is ongoing debate about the nature and extent of the decline. Uncertainty remains about whether older adults carry out early selection using the same mechanisms as young adults. Specifically, do the age groups differ in the degree to which they rely on enhancement of neural activity when attending to stimuli, or suppression of neural activity when ignoring stimuli, or both? Moreover, it is unclear whether differences in neural activity that have been found between old and young subject groups are due to the aging process itself, or differences in executive capacity or task performance in the particular groups investigated. The current study addressed these issues by carefully matching subjects based on executive capacity, as measured by neuropsychological tests, and by employing a paradigm that could distinguish between enhancement and inhibition of neural activity.

Most studies in the literature have not explicitly addressed the challenge of minimizing group differences in cognitive abilities and task performance in order to interpret changes in neural activity that are specifically due to age. Without accounting for these issues, observed differences between groups in neural activity may not be the result of age, but other factors (Daffner et al., 2011; Daselaar and Cabeza, 2005; Riis et al., 2008). One strategy has been to match groups for task performance (often by reducing the demands on older subjects). However there are disadvantages to this approach (Braver et al., 2010; Daselaar and Cabeza, 2005), as the behavioral performance of subjects in an experiment is often dependent on the particular requirements of a task and cannot be readily generalized to different experimental conditions. Daselaar and Cabeza (2005) argue in favor of grouping subjects on the basis of a battery of neuropsychological tasks that are standardized and therefore generalizable. Due to strong support for the idea that selective attention reflects top-down control mechanisms (de Fockert et al., 2001; Gazzaley et al., 2008; Rissman et al., 2009; Zanto et al., 2011), we made an effort to match age groups in terms of executive capacity using two strategies. Under one method, young and old subjects performed at a similar level (top third) relative to age-appropriate norms on neuropsychological tests. One concern with this approach is that although old and young subjects may have comparable performance relative to age-matched norms, the non-adjusted scores of older subjects on tests of executive function would be much lower than that of young subjects. To address this issue, a second group of young adults was selected whose performance on neuropsychological tests matched the non-age adjusted scores of old subjects.

Another limitation of the method typically employed to investigate selective attention is that it cannot distinguish between mechanisms of neural enhancement and suppression that may differentially change with age. Traditionally, selective attention is studied by comparing neural activity under attend vs. ignore conditions in response to the same physical stimuli. This method is able to establish whether there is a difference between attending and ignoring, but cannot determine whether the difference reflects increased activity under the attend condition, reduced activity under the ignore condition, or both (Daffner et al., 2012a). One infrequently used strategy to address this issue has been to include a condition that is attentionally neutral with respect to the feature under consideration. For example, in a study by Gazzaley et al. (2008), young and old adult subjects were shown a series of faces and scenes under four experimental conditions and were instructed to attend to faces, scenes, both faces and scenes, or just passively view the stimuli. Young adults exhibited both 
significant enhancement (attend $>$ passive view) and suppression (passive view $>$ ignore) of the ERP measures used to index early selective attention. In contrast, old adults exhibited only enhancement, but not suppression, which led the authors to conclude that older adults demonstrate a selective deficit in inhibiting task-irrelevant information during early stages of visual processing. Of particular importance to the goals of the current study, when the analysis was limited to the older subjects who were top performers on the task, there were no age-related differences in measures of suppression, suggesting that task performance and not age per se had a major influence. Additional research was needed to determine the extent to which old and young adults differ in neural processing when subject groups are carefully matched for important variables, such as executive capacity or task performance, and that uses methods for distinguishing between enhancement and inhibition of neural activity.

The current investigation employed a condition that was attentionally neutral with respect to color. Subjects were shown a series of red and blue letters, with specific letters designated as targets. Under the color-selective attention (SA) task, subjects were told to respond to target letters in a designated color and to ignore stimuli in the other color. Under the color-neutral attention (NA) task, subjects were shown physically identical stimuli and told to respond to target letters that appeared in either color. (Figure 1 illustrates an experimental run.) On the basis of prior work with young adults who participated in this experimental paradigm (Daffner et al., 2012a; Daffner et al., 2012b), the anterior Selection Positivity (SP) was chosen as an index of selective attention because it was the earliest ERP component to exhibit a differential response to stimuli based on task relevance. The anterior SP is an endogenous potential with a frontocentral distribution and a time course between $~ 150-300$ ms post stimulus presentation, which is measured as the difference in the size of the response between conditions (Daffner et al., 2012a; Kopp et al., 2007; Martin-Loeches et al., 1999; Van Der Stelt et al., 1998). The anterior SP has been interpreted either as a marker of a detection process sensitive to stimulus features, such as color, orientation, or size that have been specified by task instructions as being significant (Luck and Hillyard, 1994) or as a frontally mediated index of the motivational salience of a stimulus based on task relevance (Potts and Tucker, 2001; Riis et al., 2009).

We hypothesized that under the SA task, selective attention to specific features of a stimulus (e.g., color) would modulate operations elicited under the NA task. For example, if the size of the SP component were larger under the Attend (A) condition than under the Neutral (N) and Ignore (I) conditions, with no difference between the latter two (represented as $\mathrm{A}>\mathrm{N}=$ I), it would indicate that the difference between the Attend and Ignore conditions is explained by the enhanced activity involved with selection of specific features (color), not required under the Neutral condition $(A>N)$. There would be no suggestion of reduced activity under the Ignore relative to Neutral conditions, as both conditions elicit a similar level of activity $(\mathrm{N}=\mathrm{I})$. By contrast, if the size of the SP were larger under the Attend and Neutral conditions than the Ignore condition, with no difference between the former two (represented as A = N > I), it would indicate that there was no increase of neural activity associated with the selective attention operations beyond those involved with the more general process of directing attention to stimuli $(A=N)$. This pattern would also suggest that there was less neural activity under the Ignore condition than under the Neutral condition. In keeping with other studies (Gazzaley et al., 2005a; Gazzaley et al., 2005b), we interpret the $\mathrm{N}>\mathrm{I}$ pattern as representing suppression of activity under the Ignore condition (Daffner et al., 2012a).

If old and young subjects matched for executive capacity based on both age-appropriate norms and non-age adjusted scores differ in the pattern of SP response, it would suggest that age and not executive capacity is the most pertinent variable. A failure of old subjects to exhibit reduced activity under the Ignore relative to the Neutral condition, as observed 
among young subjects (Daffner et al., 2012a), would suggest diminished suppression of neural activity in response to stimuli that were supposed to be ignored. Such a result would be supportive of the inhibitory-deficit hypothesis of cognitive aging (Dempster, 1992; Gazzaley et al., 2008; Hasher and Zacks, 1988).

\section{Results}

\subsection{Participants}

Forty subjects completed this study: 12 young subjects with high executive capacity (mean age $=22.6(1.7)), 13$ young subjects with average executive capacity (mean age $=22.7$ (2.7)), and 15 old subjects with high executive capacity (mean age $=73.9$ (3.7)). High and average executive capacity were defined on the basis of performance relative to published age-matched norms. There were an additional two young-high capacity, one young-average capacity and three old-high capacity subjects who were excluded due to excessively noisy data. See Table 1 for subject characteristics, including demographic information, neuropsychological test performance, and estimated intelligence quotient (IQ) for each age group, as well as pertinent statistical analyses. When using age-appropriate norms for the tests of executive function, the groups differed in their overall percentile performance $\left(\mathrm{F}_{2,37}\right.$ $=37.34, \mathrm{p}<.0001)$. As expected, young-average subjects had a lower percentile score (54.0 (11.5)) than young-high subjects (80.3 (8.4)) and old-high subjects (81.5 (7.5)), with no difference between the latter two groups (young-average $<$ young-high, $\mathrm{p}<.0001$; youngaverage $<$ old-high, $\mathrm{p}<.0001$; young-high $=$ old-high, $\mathrm{p}>0.7$ ). When applying young-adult norms to all three groups, there also was an effect of group $\left(\mathrm{F}_{2,37}=36.41, \mathrm{p}<.0001\right)$, but the pattern was very different. Young-high subjects had a higher percentile score than young-average (54.0 (11.5)) and old-high groups (52.7 (7.3)), with no difference between the latter two groups (young-high $>$ young-average, $\mathrm{p}<.0001$; young-high $>$ old-high, $\mathrm{p}<$. 0001 ; young-average $=$ old-high, $\mathrm{p}>0.7$ ). The three groups did not differ in number of years of education or estimated IQ according to the American National Adult Reading Test (AMNART) (Ryan and Paolo, 1992).

\subsection{Behavior}

Table 2 presents the pertinent behavioral data. Note that task demands were made easier for old subjects (4 target letters) than young subjects (5 target letters) (see section 4.1). In terms of accuracy, there was an effect of group $\left(\mathrm{F}_{2,37}=4.16, \mathrm{p}<.05\right)$, with young-average subjects having lower scores than either young-high or old-high subjects, with no difference between the latter two groups (young-average < young-high, $\mathrm{p}<.05$; young-average < oldhigh, $\mathrm{p}<.05$; young-high $=$ old-high, $\mathrm{p}>0.9$ ). There was no effect of task on accuracy and no interaction between group and task. For mean reaction time (RT), there was an effect of group $\left(\mathrm{F}_{2,37}=3.86, \mathrm{p}<.05\right)$ and an effect of task $\left(\mathrm{F}_{1,37}=16.82, \mathrm{p}<.0005\right)$, with no interaction between group and task. The effect of group was present because young-high had faster responses than either young-average or old-high, with no difference between the latter two groups (young-high $<$ young-average, $\mathrm{p}<.05$; young-high $<$ old-high, $\mathrm{p}<.05$; youngaverage $=$ old-high, $p>0.5$ ). The task effect was due to RTs being slower under the SA than NA task.

\subsection{Anterior Selection Positivity (SP)}

This paper focused on the impact of aging on the anterior SP. Main effects or interactions that did not include the factor of age, as well as non-significant results, are not presented, unless of particular theoretical interest. Grand average ERPs for young-high, young-average and old-high subjects to standard stimuli under the Attend, Ignore, and Neutral conditions were computed for 10 Regions of Interest (ROIs) (Fig. 2) and are presented in Figure 3. Representative ROIs are featured in subsequent figures, as described below. Figure 4a 
illustrates the grand average ERPs for anterior ROIs (LAL, RAL, CF, LAM, RAM) and Figure $4 \mathrm{~b}$ shows the surface potential maps of the Attend-Ignore, Attend-Neutral, and Neutral-Ignore difference waves within the temporal window of the SP in response to standard stimuli. Figure 5 is a bar graph illustrating the mean amplitude ( \pm SEM) of the difference waves (Attend - Ignore, Attend - Neutral, Neutral - Ignore) for each subject group.

2.3.1. SP Latency-An analysis of variance (ANOVA) for the SP latency (A-I) revealed an effect of group $\left(F_{2,37}=5.20, p<.02\right)$, which was present because the mean latency of old-high subjects (213 (35) $\mathrm{ms}$ ) was later than that of young-high (190 (10) ms) and youngaverage (183 (25) ms) subjects, with no difference between the latter two groups (old-high > young-high, $\mathrm{p}<.03$; old-high $>$ young-average, $\mathrm{p}<.01$; young-high $=$ young-average, $\mathrm{p}>$ 0.4 ). Time course analysis using repeated measures ANOVA (A vs. I) performed on $25 \mathrm{~ms}$ epochs between 150-300 $\mathrm{ms}$ in response to standard stimuli, demonstrated that the onset of the SP was $\sim 50 \mathrm{~ms}$ earlier for young subjects than old subjects (Table 3 ).

2.3.2. Traditional measurement of SP amplitude (A vs. I)-The amplitude of the anterior SP was measured for both young subject groups as the mean value between 130$230 \mathrm{~ms}$, and for the old subject group between 165-265 ms at the 5 anterior ROIs (Fig. 3). These intervals reflect the approximate peak latency of the anterior SP $\pm 50 \mathrm{~ms}$ for the different groups. An initial 3-group x 2-condition (Attend vs. Ignore) ANOVA demonstrated an effect of group $\left(\mathrm{F}_{2,37}=9.49, \mathrm{p}<.001\right)$ and condition $\left(\mathrm{F}_{1,37}=31.10, \mathrm{p}<.0001\right)$. The group effect was present because the overall size of the electrophysiological response within the SP temporal window, collapsed across conditions, was larger for old subjects than for young subjects. The effect of condition was due to the mean amplitude being larger under the Attend condition than Ignore condition. Of particular importance to the study's objectives, the magnitude of the difference between Attend and Ignore was similar for all three groups (no condition $x$ group interaction, $p>0.7$ ), regardless of ROI (no condition $x$ group $x$ ROI interaction, $\mathrm{p}>0.5$ ).

\subsubsection{Measurement of enhancement and suppression of neural activity (A vs.}

$\mathbf{N}$ vs. I)-Electrophysiological responses under the Attend and Ignore conditions were then compared to those under the Neutral condition to help determine if the differences observed between the Attend and Ignore conditions represented increased activity under Attend, reduced activity under Ignore, or both. For young-high subjects, a 3-condition x 5-ROI ANOVA revealed an effect of condition $\left(\mathrm{F}_{2,22}=4.63, \mathrm{p}<.05\right)$, which was due to the mean amplitude being larger under both the Attend condition and the Neutral condition than under the Ignore condition, with no difference between the Attend and Neutral conditions ( $A=N$ $>\mathrm{I} ; \mathrm{A}>\mathrm{I}(\mathrm{p}<.01), \mathrm{N}>\mathrm{I}(\mathrm{p}<.05), \mathrm{A}=\mathrm{N}(\mathrm{p}>0.3))$. (See Fig. 5.) The magnitude of the difference between conditions was similar across the 5 anterior ROIs (no condition $x$ ROI interaction, $\mathrm{p}>0.5$ ).

Young-average subjects exhibited a similar pattern: the ANOVA indicated an effect of condition $\left(\mathrm{F}_{2,24}=4.32, \mathrm{p}<.05\right)$ which was present because the mean amplitude was larger under both the Attend and the Neutral conditions than under the Ignore condition, with no difference between the Attend and Neutral conditions $(\mathrm{A}=\mathrm{N}>\mathrm{I} ; \mathrm{A}>\mathrm{I}(\mathrm{p}<.01), \mathrm{N}>\mathrm{I}(\mathrm{p}$ $<.07), \mathrm{A}=\mathrm{N}(\mathrm{p}>0.4))$ (Fig. 5). This pattern of results was similar across the 5 anterior ROIs (no condition by ROI interaction, $\mathrm{p}>0.6$ ).

For old-high subjects, an ANOVA also revealed an effect of condition $\left(\mathrm{F}_{2,28}=3.68, \mathrm{p}<\right.$. $05)$. However, in contrast to the young subjects, the condition effect for old subjects was due to the mean amplitude being larger under the Attend condition than under both the Ignore condition and Neutral condition, with no difference between the Ignore and Neutral 
conditions ( $\mathrm{A}>\mathrm{I}=\mathrm{N}$; $\mathrm{A}>\mathrm{I}(\mathrm{p}<.05), \mathrm{A}>\mathrm{N}(\mathrm{p}<.05), \mathrm{I}=\mathrm{N}(\mathrm{p}>0.6))$ (Fig. 5). The magnitude of the difference between conditions also was similar across the 5 anterior ROIs (no condition x ROI interaction, $\mathrm{p}>0.6$ ).

\section{Discussion}

The purpose of this study was to investigate the nature and extent of age-related changes in selective attention to non-spatial features, as measured by the anterior SP. Many investigations of age-associated differences in neural activity underlying selective attention have not carefully controlled for pertinent variables other than age that might influence the pattern and speed of carrying out these operations. We focused on executive function because of strong evidence for its role in mediating selective attention (Desimone and Duncan, 1995; Lavie et al., 2004; Rutman et al., 2010). We achieved our goal of having old subjects matched to one group of young subjects based on age-appropriate norms for neuropsychological tests of executive functions and to another group of young subjects based on nonage adjusted norms. We were partially successful in matching groups for performance on the experimental paradigm. Making the task easier for high capacity old subjects may have allowed them to be as accurate as high capacity young subjects, but probably contributed to their being more accurate than average-capacity young subjects. On the other hand, the reduced task difficulty did not prevent old-high subjects from having slower RTs than young-high subjects, but may have facilitated their being as fast as youngaverage subjects. The impact on the generation of the SP of requiring old adults to respond to as many target letters (i.e., 5) as young adults needs to be addressed in future studies. Based on other work (Zhuravleva et al., 2012), it appears that a strong SP is elicited in old adults across tasks that vary the number of target letters. However, the SP response to 5 target letters has not yet been investigated.

The major finding of the study is the demonstration of salient age-related differences in the mechanism and speed by which subjects carried out selective attention to color, as indexed by the SP component. In both the young-high and young-average groups, the pattern of neural response indicated no enhancement under Attend relative to Neutral, but suppression of activity under Ignore relative to Neutral (summarized as A = N > I). This pattern of results differs from the one described by Gazzaley et al. (2005a; 2008), who reported that young adult subjects exhibit both enhanced neural activity under the attend relative to the neutral condition and suppressed neural activity under the ignore relative to the neutral condition, as measured by early ERPs to faces. Important differences in the kind of neutral condition employed may have affected the pattern of results. Like studies by Luck et al. (1994) and Mangun and Hillyard (1990), in our Neutral condition a subject was required to actively attend to the task, but not exercise selective attention operations. By contrast, Gazzaley et al. employed a neutral condition that involved passive viewing of visual stimuli that may have differed from the attend condition not only in terms of directed attention to a specified feature, but also the general level of attentional focus, effort, and motivation (Daffner et al., 2012a). Gazzaley et al.'s finding of enhanced neural activity in young adults under the attend relative to the passive condition may be a reflection of these other processes.

In contrast to both groups of young adult subjects, the old subjects in our study did not generate differences in neural response between the Ignore and Neutral conditions, which suggest the absence of suppressed activity under Ignore. This result is consistent with the reports of Gazzaley et al. (2005b; 2008) and Zanto et al. (2010a), who also found evidence of age-related breakdown of neural suppression. It supports the basic tenants of the inhibitory-deficit hypothesis, which propose that a core factor underlying cognitive aging is a decline in the ability of older adults to inhibit the processing of task-irrelevant stimuli 
(Dempster, 1992; Hasher and Zacks, 1988; West, 1996). Our work adds to the literature by demonstrating that the contrast between old and young subjects cannot be attributed to differences between age groups in executive capacity, which in the current study was controlled for in two ways. Rather, the difference seems to be intrinsic to the aging process itself.

The failure of old subjects to suppress neural activity under Ignore did not result in the absence of selective attention to color. In fact, the magnitude of the difference between the Attend and Ignore condition, as indexed by the amplitude of the SP, was similar for old and young subjects, consistent with other reports in the literature (Kenemans et al., 1995; Looren de Jong et al., 1988). Old subjects managed the selection demands of the task by enhancement of their neural response under the Attend relative to Neutral conditions, which as noted, was not observed in either group of young adult subjects. An appealing explanation for this age-related change is that it represents an adaptive response to counter the age-associated decline in neural function that led to the deficits in inhibition (Park and Reuter-Lorenz, 2009). It is consistent with other reports suggesting that one way in which older adults successfully carry out task requirements is by recruiting more neural activity than their younger counterparts (Cabeza et al., 2002; Reuter-Lorenz et al., 2000; Riis et al., 2008). The extent to which this apparent compensatory mechanism is limited to older individuals with high executive capacity remains to be established.

Our results also indicate that there was substantial age-related slowing in the execution of cognitive operations involving selective attention, as indexed by delays in the onset and peak latency of the SP. These findings are in agreement with several other reports in the literature (Czigler, 1996; Kenemans et al., 1995; Zanto et al., 2010b). Because our study controlled for group differences in executive capacity and to some extent performance on the experimental task, it allows us to make a strong case that the slowed processing speed observed among older subjects was the result of the aging process and not confounding factors.

Future studies are needed to determine the applicability of our findings to non-spatial features besides color, and to individuals of different age groups, matched for average, rather than high executive capacity. It is also important to determine if a similar pattern of age-related change is observed for old-old subjects as was seen in young-old subjects, and to discover whether these changes begin as early as middle-age. In addition, future research will need to examine the costs to subsequent processing of the observed age-related delays in selective attention and the reliance on neural enhancement rather than neural suppression to carry out these operations.

\section{Experimental Procedure}

\subsection{Participants}

Subjects were recruited through community announcements in the Boston metropolitan area, including the Harvard Cooperative Study on Aging. All subjects underwent informed consent approved by the Partners Human Research committee and a detailed screening evaluation that included a structured interview to obtain a medical, neurological, and psychiatric history, a formal neurological examination, the completion of a neuropsychological test battery, and questionnaires surveying mood and socioeconomic status. Participants were between 18 and 32 years or 65 and 80 years of age. To be included in this study, participants had to be English-speaking, have $\geq 12$ years of education, a Mini Mental State Exam (MMSE) score (Folstein et al., 1975) 226 , and an estimated IQ on the AMNART $\geq 100$. Subjects were excluded if they had a history of CNS diseases or major psychiatric disorders based on DSM-IV criteria (American Psychiatric Association, 1994), a 
history of clinically significant medical diseases, corrected visual acuity worse than 20/40 (as tested using a Snellen wall chart), a history of clinically significant audiological disease, a Beck Depression Inventory (Beck and Steer, 1987) (for young subjects) or a Geriatric Depression Scale (Yesavage et al., 1982) (for old subjects) score of $\geq 10$, were unable to distinguish between the color red and blue, or focal abnormalities on neurological examination consistent with a CNS lesion. Subjects were paid for their time.

Subjects were selected on the basis of their performance on neuropsychological tests of executive function. Although there is no universally accepted operational definition of executive functions, we followed the suggestion of many investigators who emphasize processes that include working memory, initiation, monitoring, and inhibition, and advocate the use of at least several neuropsychological tests to assess this complex group of functions (Chan et al., 2008; Delis et al., 2001; Spreen and Strauss, 1998). We selected tests that had well established norms across a wide range of ages. Tests of executive capacity included: 1) Digit Span Backward subtest of the Wechsler Adult Intelligence Scale-IV (WAIS-IV) (Wechsler, 2008), which measures the maintenance and manipulation operations of working memory; 2) Controlled Oral Word Association Test (COWAT) (Ivnik et al., 1996), which indexes initiation, self-generation, and monitoring; 3) WAIS-IV Letter-Number Sequencing, which assesses maintenance, monitoring, and manipulation; 4) WAIS-IV Digit-Symbol Coding, which assesses sustained attention/persistence, cognitive speed, and efficiency; 5) Trail-Making Test Parts A and B (Reitan and Wolfson, 1985), which measures planning/ sequencing, set shifting, and inhibition. A composite (average) score on all tests of executive capacity was computed for each subject as described below.

Old and young subjects were matched on the basis of executive capacity using two methods. Consistent with suggestions in the aging literature, the first method matched groups according to performance relative to age-appropriate norms (i.e., percentile scores) (Daffner et al., 2006; Daffner et al., 2007; Daselaar and Cabeza, 2005; Riis et al., 2008). Old and young subjects were included if they exhibited high executive capacity, as defined by a composite score in the top third ( $\geq 67^{\text {th }}$ percentile). A second method was employed in which the percentile scores for the old subject group were not based on norms for agematched peers, but rather norms for young adults. Another group of young subjects was recruited whose percentile performance relative to young adult norms matched the performance of the old subjects relative to young adult norms. A review of performance using age-appropriate norms suggested that the raw scores of young subjects with average capacity $\left(33^{\text {rd }}-66^{\text {th }}\right.$ percentile) would be comparable to the raw scores of old adults with high capacity. Thus, three groups were studied: old-high executive capacity, young-high executive capacity, and young-average executive capacity subjects, labeled according to how they performed relative to age-appropriate norms. Also, pilot data suggested that despite matching for executive capacity, old subjects still performed worse on the experimental task. To help minimize group differences in performance, task demands were made easier for old subjects. The number of target letters chosen for each age group was based on pilot data: young subjects responded to 5 target letters and old subjects responded to 4 target letters. This strategy was employed to allow us to draw inferences about agerelated differences in neural activity and not performance-related differences.

\subsection{Experimental Procedures}

The experiment consisted of two related tasks: a color-selective attention (SA) task from which the Attend (A) and Ignore (I) conditions were extracted, and a color-neutral attention (NA) task from which the Neutral (N) condition was derived. In both tasks, subjects were shown physically identical sets of stimuli, which consisted of a series of letters presented in either the color red or the color blue, and were asked to respond to specific target letters. Young subjects responded to 5 target letters and old subjects responded to 4 target letters. In 
the SA task, subjects were instructed to pay attention to letters appearing in the designated color while ignoring letters appearing in the other color, and to respond by button press to target letters appearing in the designated color only. In the NA task, subjects were instructed to pay attention to all letters regardless of color. Under both tasks, subjects were asked to respond as quickly and as accurately as possible. Practice trials preceded each set of experimental trials. All subjects participated in both tasks, the order of which was counterbalanced. To reduce potential order effects, each task was presented during a different experimental session, separated by at least two weeks. The hand used for the target response was counterbalanced across subjects, as was the attended color in the SA condition. Additionally, the specific letters selected as targets differed between the NA and the SA tasks.

Each task included 800 stimulus trials divided into 8 blocks. Under both tasks, stimuli appeared one at a time within a fixation box that remained on the screen at all times and subtended a visual angle of $\sim 3.5^{\circ} \times 3.5^{\circ}$ at the center of a high-resolution computer monitor. Half of the stimuli appeared in the color red and half in the color blue, in randomized order. Target stimuli (SA: 7.5\% in attend color; $7.5 \%$ in ignore color; NA: $7.5 \%$ probability overall, $3.75 \%$ in each color) were 4 (for old) or 5 (for young) designated upper case letters and standard stimuli (SA: $70 \%$ overall; $35 \%$ in each color; NA: $77.5 \%$ overall, $38.75 \%$ in each color) were any non-target upper case letters. Fillers accounted for the remainder of the stimuli presented. Visual stimuli subtended an angle of $2.5^{\circ}$ along their longest dimension and were presented for $250 \mathrm{~ms}$. The inter-stimulus interval (ISI) varied randomly between 815-1015 ms (mean 915 ms) (see Fig. 1). For analytic purposes, trials under the SA task were further categorized in terms of whether the stimuli presented were in the attend or the ignore color. The Attend condition consisted of all stimuli in the designated color; the Ignore condition consisted of all stimuli in the non-designated color.

\subsection{ERP Recordings}

An ActiveTwo electrode cap (Behavioral Brain Sciences Center, Birmingham, UK) was used to hold to the scalp a full array of $128 \mathrm{Ag}-\mathrm{AgCl}$ BioSemi (Amsterdam, The Netherlands) "active" electrodes whose locations were based on a pre-configured montage. Electrodes were arranged in equidistant concentric circles from the International 10-20 system position Cz. In addition to the 128 electrodes on the scalp, 6 mini bio-potential electrodes were placed over the left and right mastoid, beneath each eye, and next to the outer canthi of the eyes to check for eye blinks and vertical and horizontal eye movements. EEG activity was digitized at a sampling rate of $512 \mathrm{~Hz}$.

\subsection{Data Analysis}

Demographic variables and overall percentile performance on the neuropsychological tests for the three groups were compared using one-way ANOVAs. Mean target accuracy and mean RT were measured separately in the SA and NA conditions. A response was considered a hit if it occurred between 200-1000 ms after stimulus presentation. Overall target accuracy was determined by Percent Target Hits (target stimuli correctly responded to) - Percent False Alarms (stimuli incorrectly identified as targets). One-way ANOVAs were employed to evaluate accuracy and RT, with task (SA and NA) as within-subject variables, and subject group as the between-subject variable.

EEG data were analyzed using ERPLAB (www.erpinfo.org/erplab) and EEGLAB (Delorme and Makeig, 2004) toolboxes that operate within the MATLAB framework. Raw EEG data were resampled to $256 \mathrm{~Hz}$ and referenced off-line to the algebraic average of the right and left mastoids. EEG signals were filtered using an IIR filter with a bandwidth of $0.03-40 \mathrm{~Hz}$ (12 dB/octave roll-off). Eye artifacts were removed through an independent component 
analysis. Individual bad channels were corrected with the EEGLAB interpolation function. EEG epochs for the two stimulus types (standard stimuli, target hits/target-like stimuli) across three attention conditions (Attend, Ignore, Neutral) were averaged separately. The sampling epoch for each trial lasted for $1200 \mathrm{~ms}$, including a $200 \mathrm{~ms}$ pre-stimulus period that was used to baseline correct the ERP epochs. Trials were discarded from the analyses if they contained baseline drift or movement artifacts greater than $90 \mu \mathrm{V}$. Only trials with correct responses were included in the analyses.

ROIs across the scalp were designated and labeled Centro-Frontal (CF), Left Anterior Lateral (LAL), Right Anterior Lateral (RAL), Left Anterior Medial (LAM), Right Anterior Medial (RAM), Left Posterior Medial (LPM), Right Posterior Medial (RPM), Left OccipitoTemporal (LOT), Right Occipito-Temporal (ROT), and Centro-Occipital (CO) (see Fig. 2). Each region reflected a cluster of 7 electrode sites. Only ERPs to standard stimuli were analyzed here to avoid the potential confounding influence of motor components associated with responses to target stimuli under the Attend and Neutral conditions, but not the Ignore condition.

The latency of the SP was measured as the local positive peak latency for the Attend Ignore (AI) difference wave between 100-275 ms at anterior ROIs (CF, LAL, RAL, LAM, RAM). ERP latencies for the SP were analyzed using ANOVA, with ROI as within-subject variables and age as the between-subject variable. Of note, only the A-I difference wave was used to compute latency because both young and old subjects exhibited robust differences between the Attend and Ignore conditions. In contrast, only the young subjects demonstrated differences between the Neutral and Ignore conditions, and only the old subjects exhibited differences between Attend and Neutral conditions. Because of concerns about the potential impact of high frequency noise on peak latency values (Luck, 2005), the latency results were confirmed by time-course analyses. Repeated measure ANOVAs were performed separately on the three groups to determine the temporal epochs ( 25 ms duration) between 150 and 300 $\mathrm{ms}$ in which mean values showed a reliable difference the Attend and Ignore conditions.

The size of the SP was derived from the mean amplitude of the $100 \mathrm{~ms}$ interval centered at the mean local peak latency for each age group. Because we were interested in the traditional measurements of the SP, we began the analysis of this component by comparing only the Attend and Ignore conditions to determine if there was an age-related difference in the magnitude of the overall modulation of response by attention, using ANOVA with attention condition (Attend and Ignore), and ROI as within-subject variables, and subject group as the between-subject variable. Then, we examined whether the pattern of response varied across groups by including the Neutral condition in the analysis. Specifically, we sought to determine if the difference in electrophysiological response between Attend and Ignore conditions was due to enhanced response under Attend (by examining Attend vs. Neutral), suppressed response under Ignore (by examining Ignore vs. Neutral), or both. Given the limited number of subjects in the current study, we believed that within-subject comparison of responses across conditions was the most promising approach to reducing the variance and effectively addressing this issue. Thus, for each group, ERPs were analyzed using ANOVA, with attention condition (Attend, Ignore, Neutral), and ROI as withinsubject variables. In general, analyses that yielded significant interactions between age and condition or ROI resulted in planned contrasts between levels of the variable. The GeisserGreenhouse correction was applied for all repeated measures with greater than 1 degree of freedom. 


\section{Acknowledgments}

This research was funded in part by NIA grant R01 AGO17935 and by generous support from the Wimberly family, the Muss family, and the Mortimer/Grubman family. The authors would like to thank Marissa Keppley for her excellent administrative assistance, and Katherine Mott for her technical assistance.

\section{References}

1. American Psychiatric Association. Diagnostic and Statistical Manual of Mental Disorders. 4. Washington, D.C: American Psychiatric Association; 1994.

2. Beck, AT.; Steer, RA. Beck Depression Inventory: Manual. San Antonio, TX: The Psychological Corporation; 1987.

3. Braver TS, Cole MW, Yarkoni T. Vive les differences! Individual variation in neural mechanisms of executive control. Curr Opin Neurobiol. 2010; 20:242-250. [PubMed: 20381337]

4. Cabeza R, Anderson ND, Locantore JK, McIntosh AR. Aging gracefully: compensatory brain activity in high-performing older adults. NeuroImage. 2002; 17:1394-1402. [PubMed: 12414279]

5. Chan RC, Shum D, Toulopoulou T, Chen EY. Assessment of executive functions: review of instruments and identification of critical issues. Arch Clin Neuropsychol. 2008; 23:201-216. [PubMed: 18096360]

6. Czigler I. Age, color processing and meaningfulness: an event-related potential study. Int J Psychophysiol. 1996; 22:25-34. [PubMed: 8799765]

7. Daffner KR, Chong H, Riis J, Rentz DM, Wolk DA, Budson AE, Holcomb PJ. Cognitive status impacts age-related changes in attention to novel and target events in normal adults. Neuropsychology. 2007; 21:291-300. [PubMed: 17484592]

8. Daffner KR, Ryan KK, Williams DM, Budson AE, Rentz DM, Wolk DA, Holcomb PJ. Increased responsiveness to novelty is associated with successful cognitive aging. J Cogn Neurosci. 2006; 18:1759-1773. [PubMed: 17014379]

9. Daffner KR, Sun X, Tarbi E, Rentz DM, Holcomb PJ, Riis JL. Does compensatory neural activity survive old-old age? NeuroImage. 2011; 54:427-438. [PubMed: 20696255]

10. Daffner KR, Zhuravleva TY, Sun X, Tarbi EC, Haring AE, Rentz DM, Holcomb PJ. Does modulation of selective attention to features reflect enhancement or suppression of neural activity? Biol Psychol. 2012a; 89:398-407. [PubMed: 22178708]

11. Daffner KR, Tarbi EC, Haring AE, Zhuravleva TY, Sun X, Rentz DM, Holcomb PJ. The influence of executive capacity on selective attention and subsequent processing. Frontiers in Human Neuroscience. 2012b; 6:1-19. [PubMed: 22279433]

12. Daselaar, SM.; Cabeza, R. Age-Related Changes in Hemispheric Organization. In: Cabeza, R.; Nyberg, L.; Park, D., editors. Cognitive Neuroscience of Aging. New York: Oxford University Press; 2005. p. 325-353.

13. de Fockert JW, Ramchurn A, Van Velzen J, Bergstrom Z, Bunce D. Behavioral and ERP evidence of greater distractor processing in old age. Brain Res. 2009; 1282:67-73. [PubMed: 19497314]

14. de Fockert JW, Rees G, Frith CD, Lavie N. The role of working memory in visual selective attention. Science. 2001; 291:1803-1806. [PubMed: 11230699]

15. Delis, D.; Kaplan, E.; Kramer, J. Delis Kaplan Executive Function System. San Antonio, TX: Psychological Cooperation; 2001.

16. Delorme A, Makeig S. EEGLAB: an open source toolbox for analysis of single-trial EEG dynamics including independent component analysis. Journal of Neuroscience Methods. 2004; 134:9-21. [PubMed: 15102499]

17. Dempster FN. The rise and fall of the inhibitory mechanism: Toward a unified theory of cognitive development and aging. Developmental Review. 1992; 12:45-75.

18. Desimone R, Duncan J. Neural Mechanisms of Selective Visual Attention. Annu Rev Neurosci. 1995; 18:193-222. [PubMed: 7605061]

19. Folstein MF, Folstein SE, McHugh PR. "Mini-Mental State". A practical method for grading the cognitive state of patients for the clinician. J Psychiatr Res. 1975; 12:189-198. [PubMed: 1202204] 
20. Gazzaley A, Clapp W, Kelley J, McEvoy K, Knight RT, D’Esposito M. Age-related top-down suppression deficit in the early stages of cortical visual memory processing. Proc Natl Acad Sci USA. 2008; 105:13122-13126. [PubMed: 18765818]

21. Gazzaley A, Cooney JW, McEvoy K, Knight RT, D’Esposito M. Top-down enhancement and suppression of the magnitude and speed of neural activity. J Cogn Neurosci. 2005a; 17:507-517. [PubMed: 15814009]

22. Gazzaley A, Cooney JW, Rissman J, D’Esposito M. Top-down suppression deficit underlies working memory impairment in normal aging. Nature Neuroscience. 2005b; 8:1298-1300.

23. Hasher L, Zacks RT. Working memory, Comprehension, and aging: A review and a new view. Psychology of learning \& motivation. 1988; 22:193-225.

24. Ivnik RJ, Malec JF, Smith GE, Tangalos EG, Petersen RC. Neuropsychological tests' norms above age 55: COWAT, BNT, MAE Token, WRAT-R Reading, AMNART, STROOP, TMT, and JLO. Clin Neuropsychol. 1996; 10:262-278.

25. Kenemans JL, Smulders FT, Kok A. Selective processing of two-dimensional visual stimuli in young and old subjects: electrophysiological analysis. Psychophysiology. 1995; 32:108-120. [PubMed: 7630975]

26. Kopp B, Tabeling S, Moschner C, Wessel K. Temporal dynamics of selective attention and conflict resolution during cross-dimensional Go-NoGo decisions. BMC Neuroscience. 2007; 8:68-83. [PubMed: 17705856]

27. Lavie N, Hirst A, de Fockert JW, Viding E. Load theory of selective attention and cognitive control. J Exp Psychol Gen. 2004; 133:339-354. [PubMed: 15355143]

28. Looren de Jong H, Kok A, van Rooy JC. Early and late selection in young and old adults: an eventrelated potential study. Psychophysiology. 1988; 25:657-671. [PubMed: 3241853]

29. Luck, SJ. An Introduction to the Event-Related Potential Technique. Cambridge: The MIT Press; 2005.

30. Luck SJ, Hillyard SA, Mouloua M, Woldorff MG, Clark VP, Hawkins HL. Effects of spatial cuing on luminance detectability: psychophysical and electrophysiological evidence for early selection. J Exp Psychol Hum Percept Perform. 1994; 20:887-904. [PubMed: 8083642]

31. Luck S, Hillyard SA. Electrophysiological correlates of feature analysis during visual search. Psychophysiology. 1994; 31:291-308. [PubMed: 8008793]

32. Lustig, C.; Hasher, L.; Zacks, RT. Inhibitory deficit theory: recent developments in a "new view". In: Gorfein, DS.; MacLeod, CM., editors. Inhibition in Cognition. Washington, DC: American Psychological Association; 2007. p. 145-162.

33. Mangun GR, Hillyard SA. Allocation of visual attention to spatial locations: tradeoff functions for event-related brain potentials and detection performance. Percept Psychophys. 1990; 47:532-550. [PubMed: 2367174]

34. Martin-Loeches M, Hinojosa JA, Rubia FJ. Insights from event-related potentials into the temporal and hierarchical organization of the ventral and dorsal streams of the visual system in selective attention. Psychophysiology. 1999; 36:721-736. [PubMed: 10554586]

35. Park DC, Reuter-Lorenz P. The adaptive brain: aging and neurocognitive scaffolding. Annu Rev Psychol. 2009; 60:173-196. [PubMed: 19035823]

36. Potts GF, Tucker DM. Frontal evaluation and posterior representation in target detection. Brain Res Cogn Brain Res. 2001; 11:147-156. [PubMed: 11240117]

37. Reitan, R.; Wolfson, D. The Halstead-Reitan Neuropsychological Test Battery: Theory and Clinical Interpretation. Tucson: Neuropsychology Press; 1985.

38. Reuter-Lorenz PA, Jonides J, Smith EE, Hartley A, Miller A, Marshuetz C, Koeppe RA. Age differences in the frontal lateralization of verbal and spatial working memory revealed by PET. $\mathrm{J}$ Cogn Neurosci. 2000; 12:174-187. [PubMed: 10769314]

39. Riis JL, Chong H, McGinnnis S, Tarbi E, Sun X, Holcomb PJ, Rentz DM, Daffner KR. Agerelated changes in early novelty processing as measured by ERPs. Biol Psychol. 2009; 82:33-44. [PubMed: 19463888]

40. Riis JL, Chong H, Ryan KK, Wolk DA, Rentz DM, Holcomb PJ, Daffner KR. Compensatory neural activity distinguishes different patterns of normal cognitive aging. NeuroImage. 2008; 39:441-454. [PubMed: 17931892] 
41. Rissman J, Gazzaley A, D'Esposito M. The effect of non-visual working memory load on topdown modulation of visual processing. Neuropsychologia. 2009; 47:1637-1646. [PubMed: 19397858]

42. Rutman AM, Clapp WC, Chadick JZ, Gazzaley A. Early top-down control of visual processing predicts working memory performance. J Cogn Neurosci. 2010; 22:1224-1234. [PubMed: 19413473]

43. Ryan J, Paolo A. A screening procedure for estimating premorbid intelligence in the elderly. Clin Neuropsychol. 1992; 6:53-62.

44. Spreen, O.; Strauss, E. A Compendium of Neuropsychological Tests: Administration, Norms, and Commentary. New York: Oxford University Press; 1998.

45. Van Der Stelt O, Kok A, Smulders FT, Snel J, Boudewijn GW. Cerebral event-related potentials associated with selective attention to color: developmental changes from childhood to adulthood. Psychophysiology. 1998; 35:227-239. [PubMed: 9564743]

46. Wechsler, D. Wechsler Adult Intelligence Scale. 4. San Antonio, TX: Pearson; 2008.

47. West R. Visual distraction, working memory, and aging. Memory and Cognition. 1999; 27:10641072.

48. West RL. An application of prefrontal cortex function theory to cognitive aging. Psychological Bulletin. 1996; 120:272-292. [PubMed: 8831298]

49. Yesavage JA, Brink TL, Rose TL, Lum O, Huang V, Adey M, Leirer VO. Development and validation of a geriatric depression screening scale: a preliminary report. J Psychiatr Res. 1982; 17:37-49. [PubMed: 7183759]

50. Zanto TP, Hennigan K, Ostberg M, Clapp WC, Gazzaley A. Predictive knowledge of stimulus relevance does not influence top-down suppression of irrelevant information in older adults. Cortex. 2010a; 46:564-574. [PubMed: 19744649]

51. Zanto TP, Rubens MT, Thangavel A, Gazzaley A. Causal role of the prefrontal cortex in top-down modulation of visual processing and working memory. Nature Neuroscience. 2011; 14:656-661.

52. Zanto TP, Toy B, Gazzaley A. Delays in neural processing during working memory encoding in normal aging. Neuropsychologia. 2010b; 48:13-25. [PubMed: 19666036]

53. Zhuravleva, T.; Haring, A.; Alperin, B.; Holcomb, P.; Rentz, D.; Daffner, K. Age-related changes in selective attention in the very old: a bottom-up or top-down problem?. Supplement of the Journal of Cognitive Neuroscience: Cognitive Neuroscience Society, Annual Meeting Program; 2012. p. 61 


\section{Highlights}

- Age-related differences in selective attention are examined using ERPs

- Executive capacity of groups are matched using age and non-age adjusted scores

- Responses under color-attend, color-ignore, and color-neutral conditions are compared

- Unlike young subjects, old subjects fail to suppress activity under color-ignore

- Old subjects may compensate by enhancing activity under color-attend 


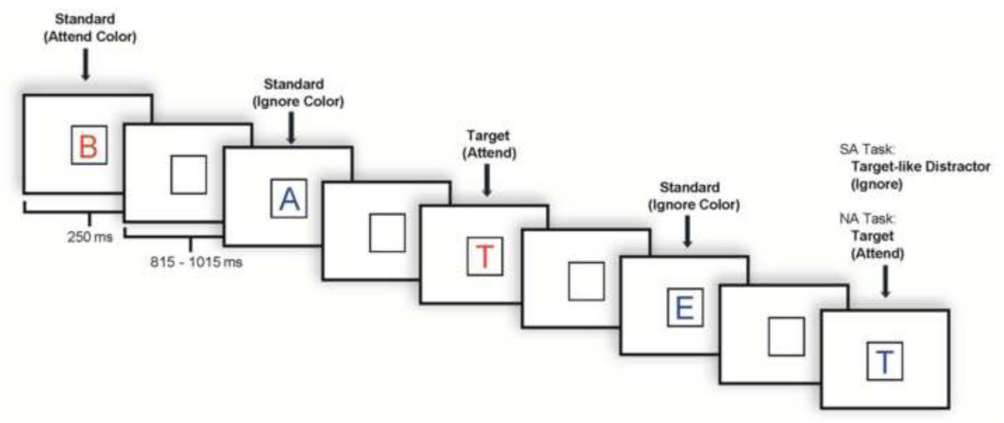

Figure 1.

Illustration of an experimental run. Subjects were shown a series of red and blue letters. Under the color-selective attention (SA) task, subjects were instructed to press a button in response to designated target letters in a specified color (Attend condition) and ignore letters in the other color (Ignore condition). Under the color-neutral attend (NA) task, subjects were instructed to respond to designated target letters in either color (Neutral condition). Young subjects responded to 5 target letters, whereas old subjects responded to 4 target letters. 


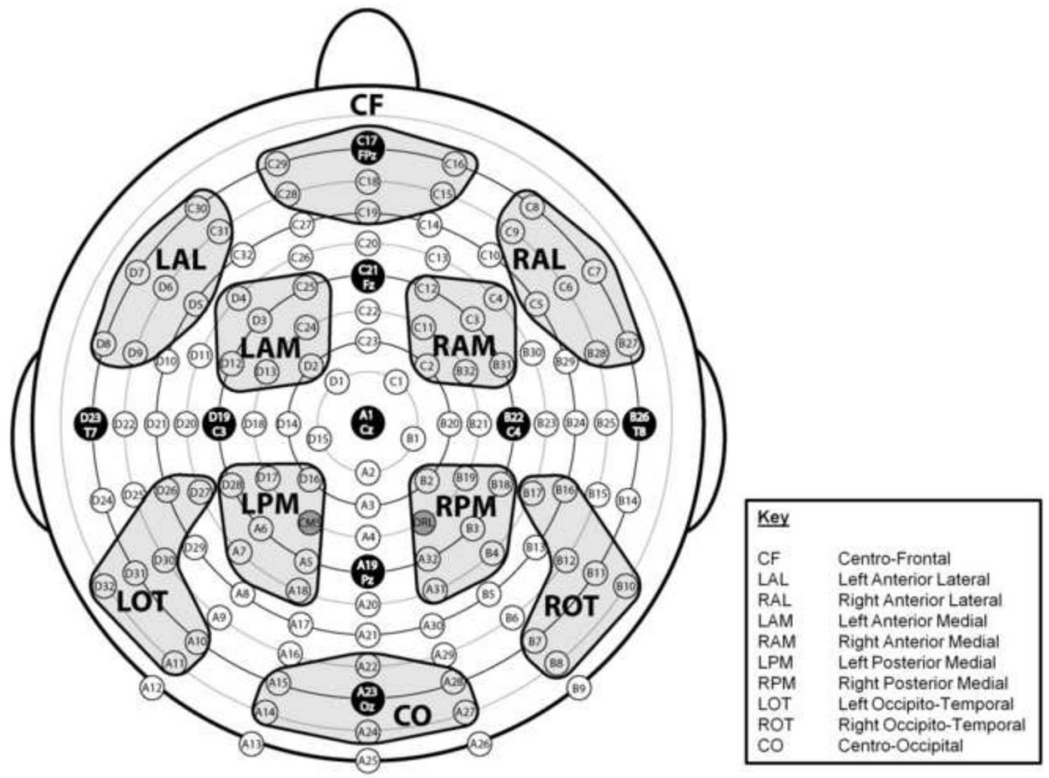

Figure 2.

Montage illustrating the location of 128 electrode sites and the 10 designated regions of interest (ROIs). 


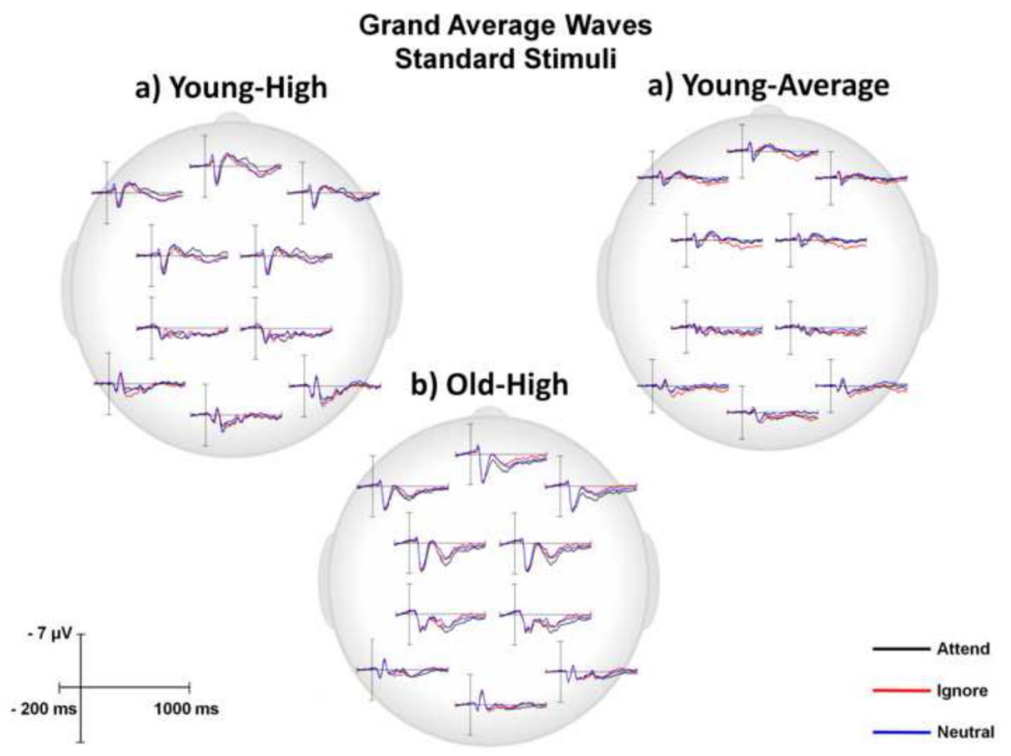

Figure 3.

Grand average ERP responses under Attend, Ignore, and Neutral conditions at all 10 ROIs in response to standard stimuli for each of the 3 subject groups. 


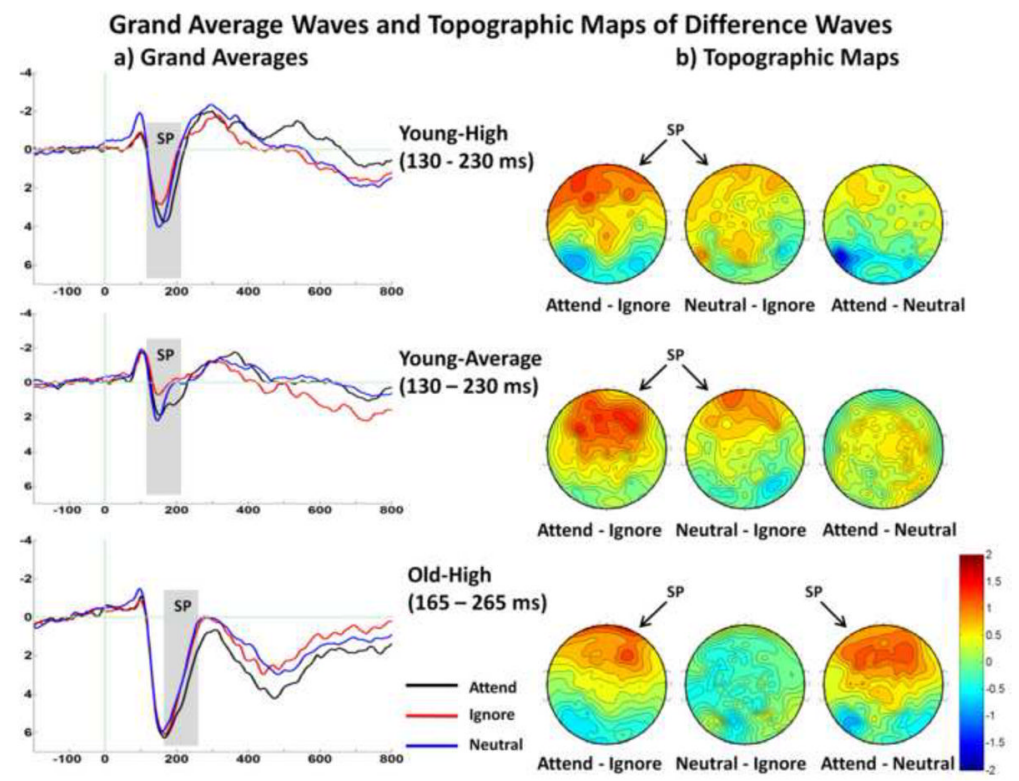

Figure 4.

a) Grand average ERP responses under Attend, Ignore, and Neutral at anterior ROIs in response to standard stimuli. The highlighted area represents the temporal interval in which the Selection Positivity (SP) was measured. b) Surface potential maps of difference waves under Attend - Ignore, Neutral - Ignore, and Attend - Neutral conditions for the SP interval in response to standard stimuli illustrating a different pattern for young and old subjects. In both groups of young subjects, an SP is generated for Attend - Ignore and Neutral - Ignore conditions, but in old subjects an SP is generated for Attend - Ignore and Attend - Neutral conditions. 

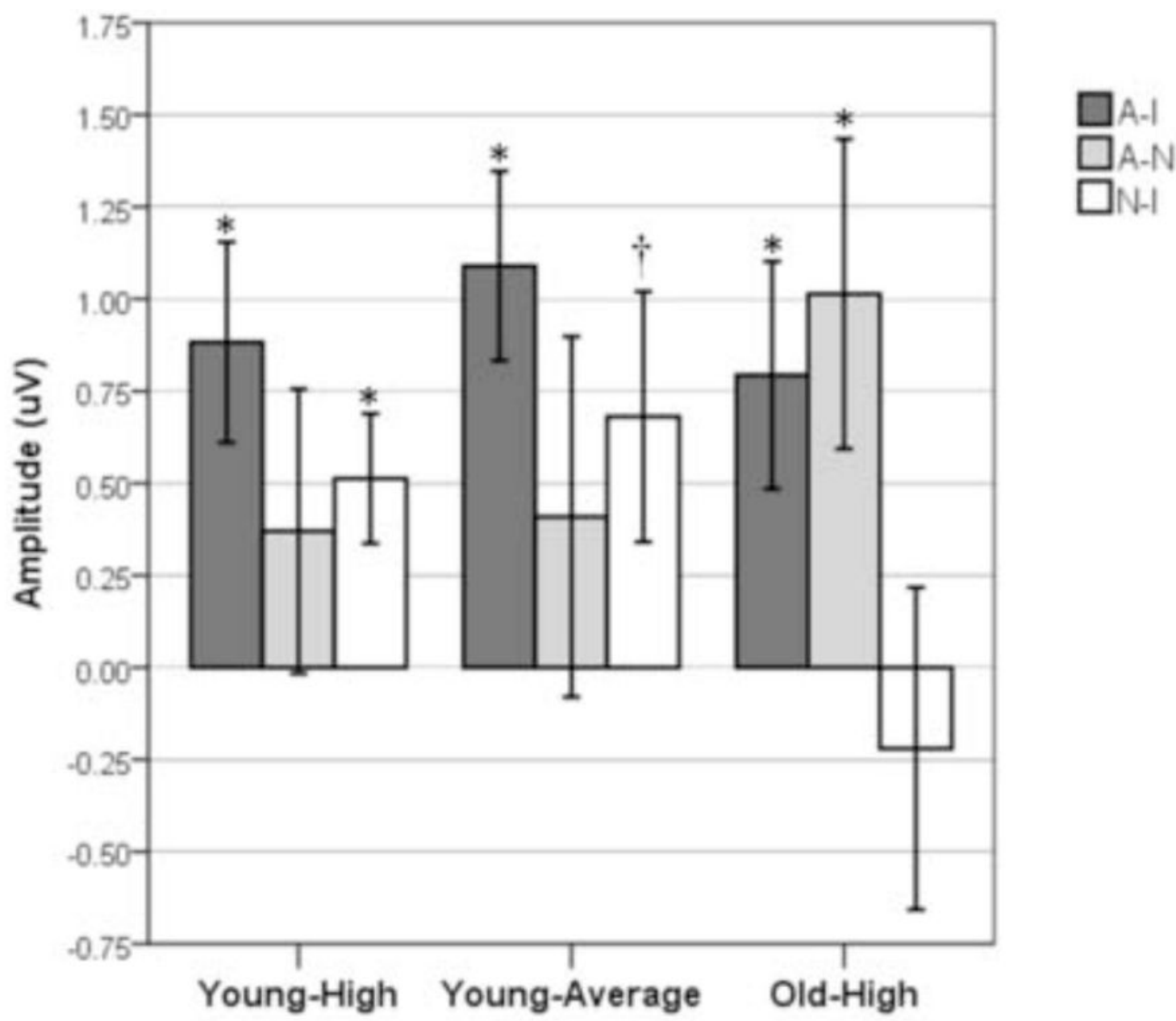

Figure 5.

Bar graph displaying the mean amplitude $( \pm$ SEM) of the difference waves (Attend - Ignore, Attend - Neutral, Neutral - Ignore) for each subject group. $*=p<.05 ; \dagger=p<.07$ based on one-sample t-tests used to determine if the mean value differed significantly from $0 \mu \mathrm{V}$. 
Table 1

Subject Characteristics (Mean(SD))

\begin{tabular}{llll}
\hline Variable & Young-High & Young-Average & Old-High \\
\hline Number of subjects & 12 & 13 & 15 \\
Gender (male:female) & $5: 7$ & $7: 6$ & $6: 9$ \\
Age * & $22.6(1.7)$ & $22.6(2.7)$ & $73.9(3.7)$ \\
EC \%ile: age-matched norms * & $80.3(8.4)$ & $54.0(11.5)$ & $81.5(7.5)$ \\
EC \%ile: young adult norms & $80.3(8.4)$ & $54.0(11.5)$ & $52.7(7.3)$ \\
Years of Education & $15.9(1.7)$ & $14.4(1.1)$ & $16.5(3.7)$ \\
AMNART & $119(4.8)$ & $114(7.7)$ & $121(8.5)$ \\
$*$ & & & \\
Effect of group, $<.001$ & & &
\end{tabular}

AMNART $=$ American National Adult Reading Test 


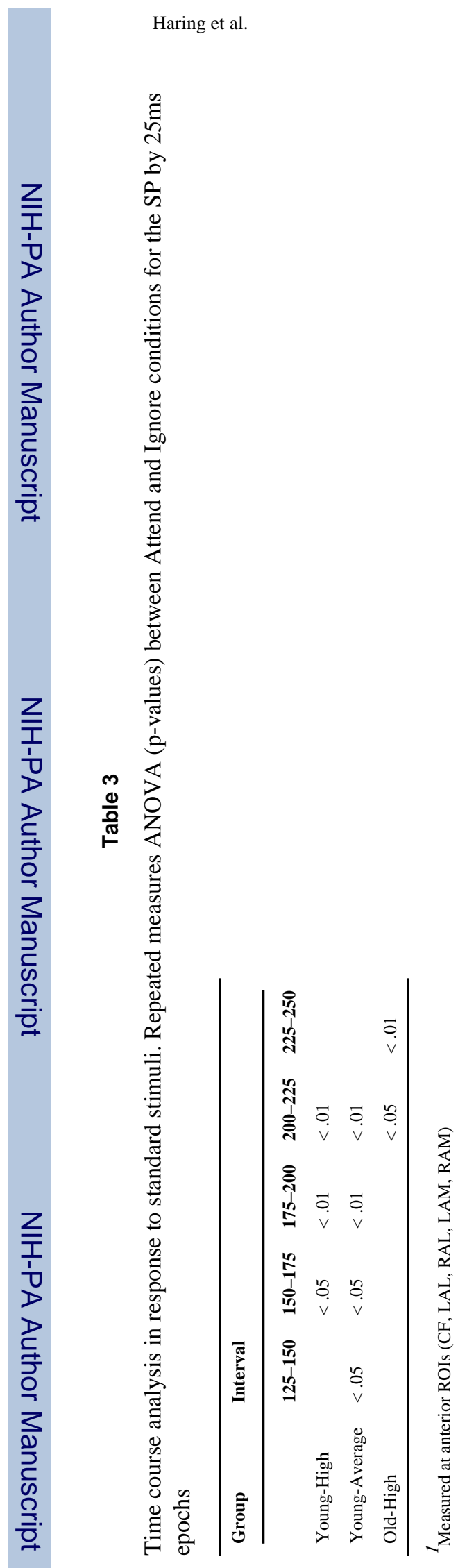

Brain Res. Author manuscript; available in PMC 2014 March 07. 